\title{
Permeability through Cellulose Membranes Grafted with Vinyl Monomers in a Homogeneous System III. Methyl Acrylate Grafted Cellulose Membranes
}

\author{
Noboru NishiOKA, Takashi KuROMATSU, Toshitaka TAKAHASHI, \\ Masakuni UNO,* and Kouichi KosAI \\ Faculty of Engineering and * Junior College division, \\ Osaka Electro-Communication University, \\ Neyagawa, Osaka 572, Japan
}

(Received June 25, 1985)

\begin{abstract}
The homogeneous grafting of methyl acrylate (MA) onto cellulose was carried out in a dimethyl sulfoxide (DMSO)-paraformaldehyde solvent system. Three kinds of membranes were prepared: membranes of graft copolymers using ammonium persulfate (APS) as initiators (APS membrane), membranes of those using azobisisobutyronitrile, and blended membranes of cellulose and poly(methyl acrylate). The diffusive permeability of solutes through water-swollen membranes, the states of water in them, and the microphase separated structures of the membranes depended on the kind of membrane. The states of intermediate water in the membranes were influenced by grafting MA onto cellulose. Permeability through the APS membranes was superior to that through the membrane cast from the DMSO solution of cellulose. The superiority of APS membranes is due to the decrease in relatively strongly interacting water components.
\end{abstract}

KEY WORDS Cellulose / Methyl Acrylate / Grafted Membrane / Diffusive

Permeability / Microphase Separated Structure / Free Water / Intermediate

Water / Bound Water/

Water soluble solutes are considered to diffuse only through water phases in waterswollen membranes. ${ }^{1-8}$ Based on the free volume theory of diffusion, Yasuda et al..$^{1-3}$ indicated that the diffusive permeability of solutes through membranes is explained by water content. A similar treatment has also been carried out for other polymer membrane systems. $^{4-8}$

Different states of water in membranes have been reported by many workers..$^{9-30}$ Some water molecules referred to as "bound water" are bound to polymer molecules through hydrogen bonding and are immobilized. Other water molecules referred to as "free water" do not take part in hydrogen bonding with polymer molecules and thus have a greater degree of mobility..$^{9-15}$ Still other water molecules interacting weakly with polymer molecules are referred to as "intermediate water" or "secondary bound water."16-30 Among them, bound water is thought to be less capable of dissolving solutes. ${ }^{31,32}$ On the other hand, it has been reported that bound water can be classified as that containing solutes and that rejecting them. ${ }^{19}$ Characterization of water relating to the diffusive permeation of solutes thus seems important for clarifying the mechanism of membrane permselectivity. Few discussions have been made about this point. ${ }^{23,26}$

In our previous papers, ${ }^{33,34}$ the homogeneous grafting of acrylonitrile (AN) onto cellulose in a dimethyl sulfoxide-paraformaldehyde (DMSO-PF) solvent system was carried out under various conditions to prepare graft copolymers of different compositions. The diffusive permeability of solutes through 
the copolymer membranes, the states of water in them, and the microphase separated structures of them were investigated. The incorporation of hydrophobic polyacrylonitrile (PAN) onto hydrophilic cellulose influenced the states of intermediate water to improve the permeability of solutes.

In this paper, homogeneous grafting onto cellulose was carried out with methyl acrylate (MA). The diffusive permeability of solutes through MA grafted cellulose membranes of various compositions was investigated. The states of water in the membranes were discussed in relation to membrane permeability.

\section{EXPERIMENTAL}

\section{Grafting and Membrane Preparation}

The homogeneous grafting of MA onto cellulose in the DMSO-PF solvent system and characterization of the graft products obtained were carried out by the method described in previous papers. ${ }^{35,36}$ The results are summarized in Table I. The viscosity-average molecular weight, $M_{v}$, of the main chain cellulose was estimated to be $16 \times 10^{4}$ from the intrinsic viscosity, $[\eta]$, obtained with cadoxen at $20.0^{\circ} \mathrm{C}^{37}$ The values of $M_{v}$ for graft poly(methyl acrylate) (PMA) were also estimated from $[\eta]$ obtained with methanol at $25.0^{\circ} \mathrm{C}^{38}$ The MA grafted cellulose was classified into two groups depending upon the grafting initiator used, i.e., ammonium persulfate (APS) or azobisisobutyronitrile (AIBN). It is known ${ }^{39}$ that the difference in initiator effects the grafting efficiency (GE) expressing the ratio of weight of graft polymer to that of polymer formed. It has been found $^{35,36,39}$ that the use of AIBN leads to less grafting efficiency because of the resonance stabilization of its radical fragments. In previous papers, ${ }^{33,34} \mathrm{AN}$ grafted membranes were classified into two groups depending upon grafting efficiency. The higher grafting efficiency (H-GE) and lower grafting efficiency (L-GE) membranes correspond to the APS and AIBN membranes in this study, respectively. It should be kept in mind that the grafted membranes used contain the homopolymer component, homo-PMA.

Table I. Characterization of grafted and blended membranes

\begin{tabular}{|c|c|c|c|c|c|c|}
\hline \multirow{2}{*}{ Sample code } & \multirow{2}{*}{$\frac{\mathrm{GE}}{\%}$} & \multicolumn{3}{|c|}{ PMA content $/ \%$} & \multirow{2}{*}{$\begin{array}{c}M_{v} \times 10^{-4} \\
\text { of } \text { graft }^{\mathrm{a}}\end{array}$} & \multirow{2}{*}{$\begin{array}{l}\text { Number } \\
\text { of grafts }\end{array}$} \\
\hline & & Overall & Graft-PMA & Homo-PMA & & \\
\hline \multicolumn{7}{|l|}{ APS Membrane } \\
\hline g-PMA 1 & 56.5 & 11.3 & 6.4 & 4.7 & 1.0 & 1.08 \\
\hline g-PMA 2 & 47.3 & 18.9 & 8.9 & 10.0 & 5.0 & 0.40 \\
\hline g-PMA 3 & 51.7 & 29.4 & 15.2 & 14.2 & 10.5 & 0.34 \\
\hline g-PMA 4 & 50.0 & 37.6 & 18.8 & 18.8 & 4.4 & 1.09 \\
\hline \multicolumn{7}{|l|}{ AIBN Membrane } \\
\hline g-PMA 11 & 17.8 & 10.1 & 1.8 & 8.3 & 25.0 & 0.02 \\
\hline g-PMA 12 & 22.2 & 21.3 & 4.7 & 16.6 & 11.0 & 0.04 \\
\hline g-PMA 13 & 14.8 & 35.1 & 5.2 & 29.9 & 15.0 & 0.09 \\
\hline \multicolumn{7}{|l|}{ Blended membrane ${ }^{b}$} \\
\hline b-PMA 1 & 0 & 10.0 & 0 & 10.0 & & \\
\hline b-PMA 2 & 0 & 20.0 & 0 & 20.0 & & \\
\hline b-PMA 3 & 0 & 30.0 & 0 & 30.0 & & \\
\hline b-PMA 4 & 0 & 40.0 & 0 & 40.0 & & \\
\hline
\end{tabular}

a Estimated from $[\eta]$ obtained in methanol at $25.0^{\circ} \mathrm{C}^{38}$

b The values of $M_{v}$ for cellulose and PMA are $16 \times 10^{4}$ and $17 \times 10^{4}$, respectively. 
The grafting mixtures were cast at room temperature on glass plates, and DMSO and unreacted monomer were allowed to evaporate at about $40^{\circ} \mathrm{C}$ under reduced pressure for $24 \mathrm{~h}$ prior to the coagulation of membranes in water. After being immersed in water for several days, the membranes were easily removed from the glass plates. The DMSO solutions of cellulose and PMA were mixed to give proper blended ratios. The blended membranes were also prepared by the same method as that described above.

\section{Diffusive Permeability}

The diffusive permeability of water soluble solutes was measured at $30.0^{\circ} \mathrm{C}$ by the method described in our previous paper. ${ }^{33}$ Seven solutes of different molecular weight were used as permeants. The values of $M_{v}$ for commercial poly(ethylene glycol) (PEG) samples were estimated from $[\eta]$ obtained with benzene at $25.0^{\circ} \mathrm{C}: 40$ PEG-IV $=3.1 \times 10^{3}$, PEG-VI $=$ $8.0 \times 10^{3}$, and PEG-XX $=3.1 \times 10^{4}$, respectively.

\section{Transmission Electron Microscopy (TEM)}

Electron micrographs were taken under a Hitachi HU-11A microscope. The membranes were stained by immersion in a $2 \%$ aqueous solution of osmic acid for one day. The copolymers of $n$-butyl methacrylate and methyl methacrylate $(9: 1$ or $8: 2$ by weight) were used as embedding media. The embedded membranes were cross-sectioned at a thickness of approximately $500 \AA$.

\section{Differential Scanning Calorimetry (DSC)}

The measurements were carried out with a SEIKO SSC/560 DSC according to the method described previously. ${ }^{34}$ The samples were cooled with liquid nitrogen at a rate of $5^{\circ} \mathrm{K} \mathrm{min}^{-1}$ to $-80^{\circ} \mathrm{C}$ and then heated at the same rate to $60-90^{\circ} \mathrm{C}$. The total water content was varied by standing the sample pans in the DSC cell at a given temperature for a given period to evaporate the water from the membranes.

\section{RESULTS AND DISCUSSION}

The dependence of diffusive permeability on the solute molecular weight for various membranes is illustrated in Figure 1. The results of our previous study ${ }^{33}$ for the commercial regenerated cellulose membrane, Cuprophan, and the membrane cast from the DMSO so-

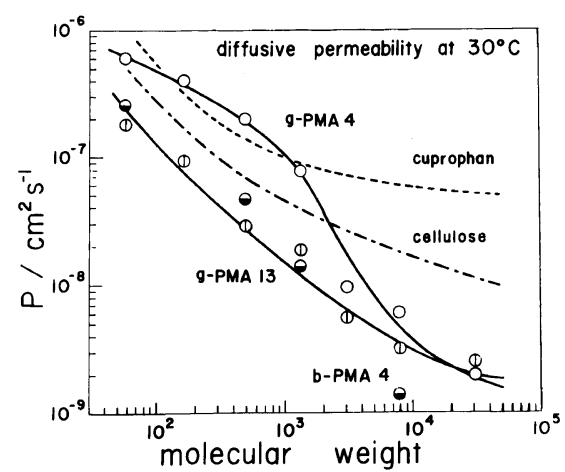

Figure 1. Molecular weight dependence of diffusive permeability for various membranes: (O) g-PMA 4 membrane: (1) g-PMA 13 membrane: (Ө) b-PMA 4 membrane; the broken line, cuprophan membrane; dash-dotted line, cellulose membrane; the solutes are, in the order of increasing molecular weight, $\mathrm{NaCl}$, uric acid, raffinose, vitamine $B_{12}$, PEG-IV, PEG-VI, and PEG-XX.

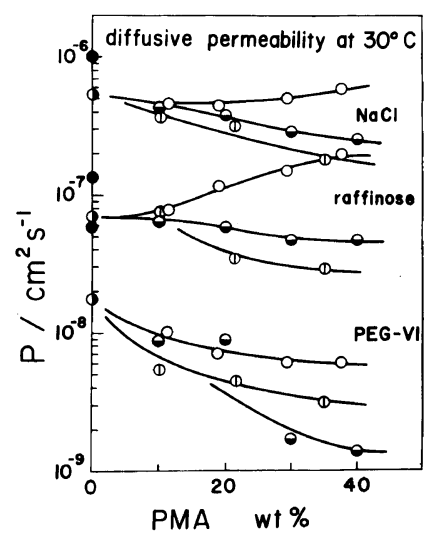

Figure 2. PMA content dependence of diffusive permeability for $\mathrm{NaCl}$, raffinose, and PEG-VI: (O) cuprophan membrane; (O) cellulose membrane; (O) APS membranes; (1) AIBN membranes; ( $\theta$ ) blended membranes. 


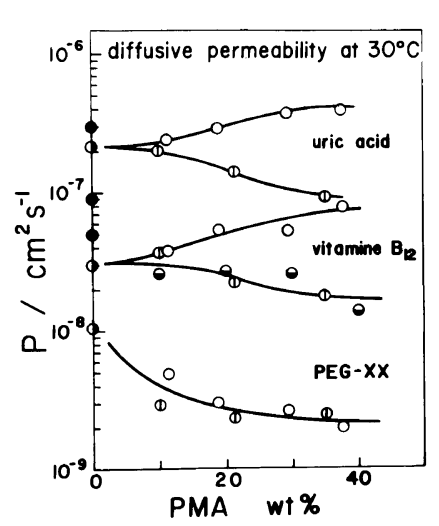

Figure 3. PMA content dependence of diffusive permeability for uric acid, vitamine $\mathrm{B}_{12}$, and PEG-XX; the symbols are the same as those in Figure 2.

lution of cellulose, designated as the cellulose membrane, are also indicated. The molecular weight dependence for the g-PMA 4 membrane, a APS membrane, differs from that for other membranes. The permeabilities of lower molecular weight solutes through the g-PMA 4 membrane are superior to those through the cellulose membrane, whereas those of three PEG samples are not superior to those through the cellulose membrane.

On the other hand, permeability through the g-PMA 13 membrane, an AIBN membrane, and the b-PMA 4 membrane, a blended membrane, is several times lower than that through the cellulose membrane but their molecular weight dependence is similar to that for the cellulose membrane. In Table I, the PMA content of these three membranes is about $40 \%$ but the values of grafting efficiency differ remarkably with each other. Such a difference in the molecular weight dependence of permeability with the grafting efficiency has also been found on the AN grafted cellulose membranes. ${ }^{33}$

Figures 2 and 3 show the relationship between the PMA content and diffusive permeability for various solutes. The permeability of $\mathrm{NaCl}$ through the APS membranes increases slightly with increasing PMA content, but those of uric acid, raffinose, and vitamine
$\mathrm{B}_{12}$ increase clearly and are superior to those through the Cuprophan membrane at higher PMA content. In contrast, the permeabilities of PEG-VI and PEG-XX through the APS membranes decrease with increasing PMA content and that of PEG-XX is nearly the same as that through the AIBN membranes.

The permeabilities of all solutes investigated through the AIBN and blended membranes decrease with increasing PMA content. The permeabilities of $\mathrm{NaCl}$ and raffinose through the blended membranes are intermediate between those through the APS and AIBN membranes. But the permeability of vitamine $B_{12}$ through the blended membranes is almost the same as that through the AIBN membranes and the permeability of PEG-VI is somewhat less than that through the AIBN membranes. These results indicate that the dependence of diffusive permeability on PMA content differs not only with grafting efficiency but also the permeating solute itself.

Copolymers indicate microphase separated structures due to the incompatibility of constituent polymers. In our grafted membranes containing the homo-PMA component, the value of grafting efficiency influenced the microphase separated structures remarkably. Figure 4 shows the TEM micrographs of the APS membranes. The dark domains indicate the cellulose phases stained with osmic acid. The interfaces between the cellulose and PMA domains for each sample are not clear, indicating very fine microphase separated structures.

Figure 5 indicates the TEM micrographs of the AIBN membranes. The cellulose domain size is a little larger than that of the APS membranes and the interfaces between both phases are clearer than those of the APS membranes. In spite of the smaller PMA content in the membranes, the cellulose domains are dispersed in the continuous phase. This is probably because DMSO is a poor solvent for cellulose.

Figure 6 shows the TEM micrographs of the blended membranes. The cellulose domain size 

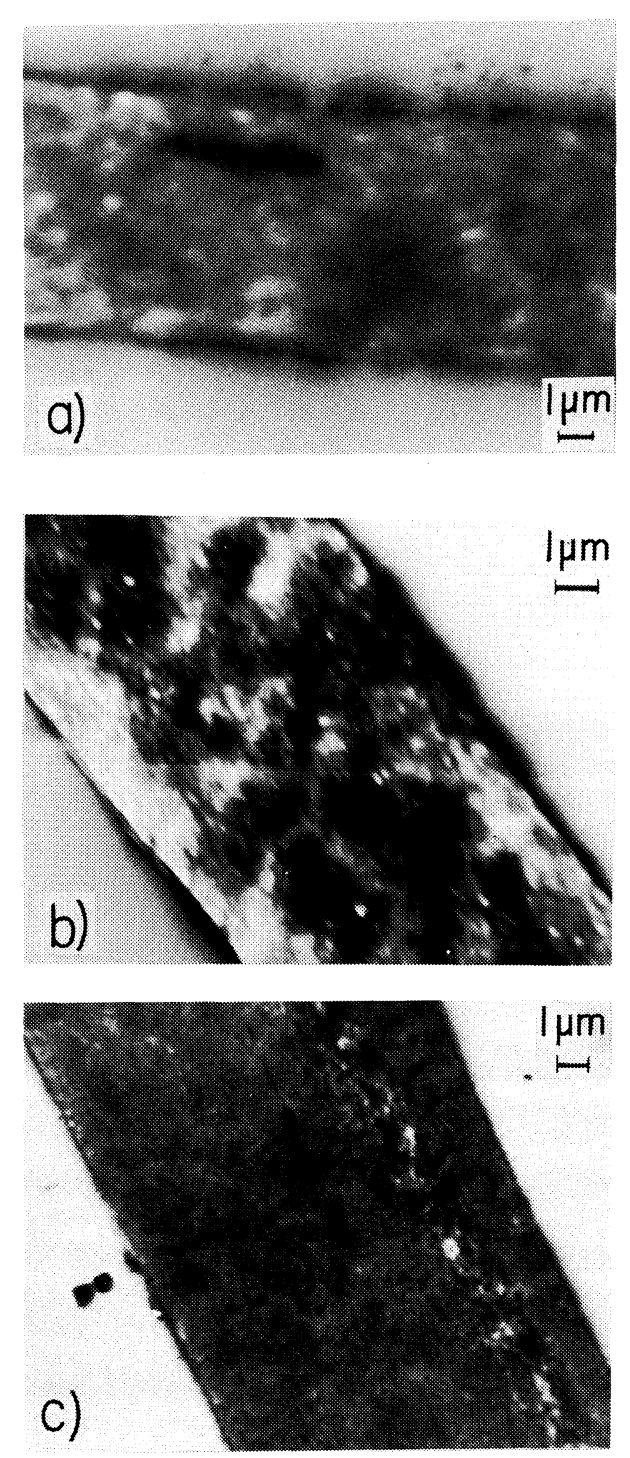

Figure 4. Transmission electron micrographs of the APS membranes stained with osmic acid: (a) g-PMA 1; (b) g-PMA 2; (c) g-PMA 4.

becomes larger with decreasing cellulose content, indicating a decrease in the compatibility of blended membranes. In Figure $6 \mathrm{a}$, the cellulose content is $90 \%$ but the dark domain fraction is small. Therefore, the gray continuous phase in Figure $6 \mathrm{a}$ would be not the PMA phase but the homogeneously blended phase of cellulose and PMA. In Figure 6b, this
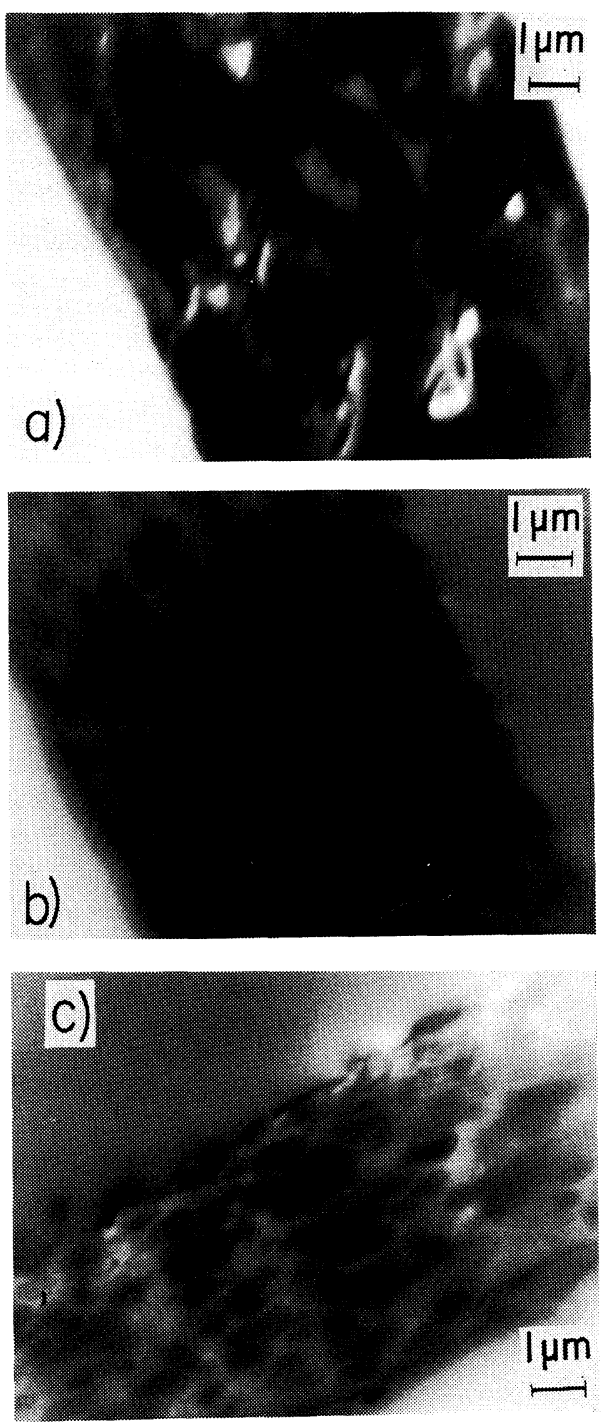

Figure 5. Transmission electron micrographs of the AIBN membranes: (a) g-PMA 11, (b) g-PMA 12; (c) gPMA 13.

expectation is confirmed since the large dark (cellulose) and small white (PMA) domains are dispersed in the continuous gray phase.

The melting and freezing DSC curves of the g-PMA 4 membrane containing different amounts of water are shown in Figure 7. Several peaks are found on both curves, revealing the existence of several states of freezing water. A comparison with the results 

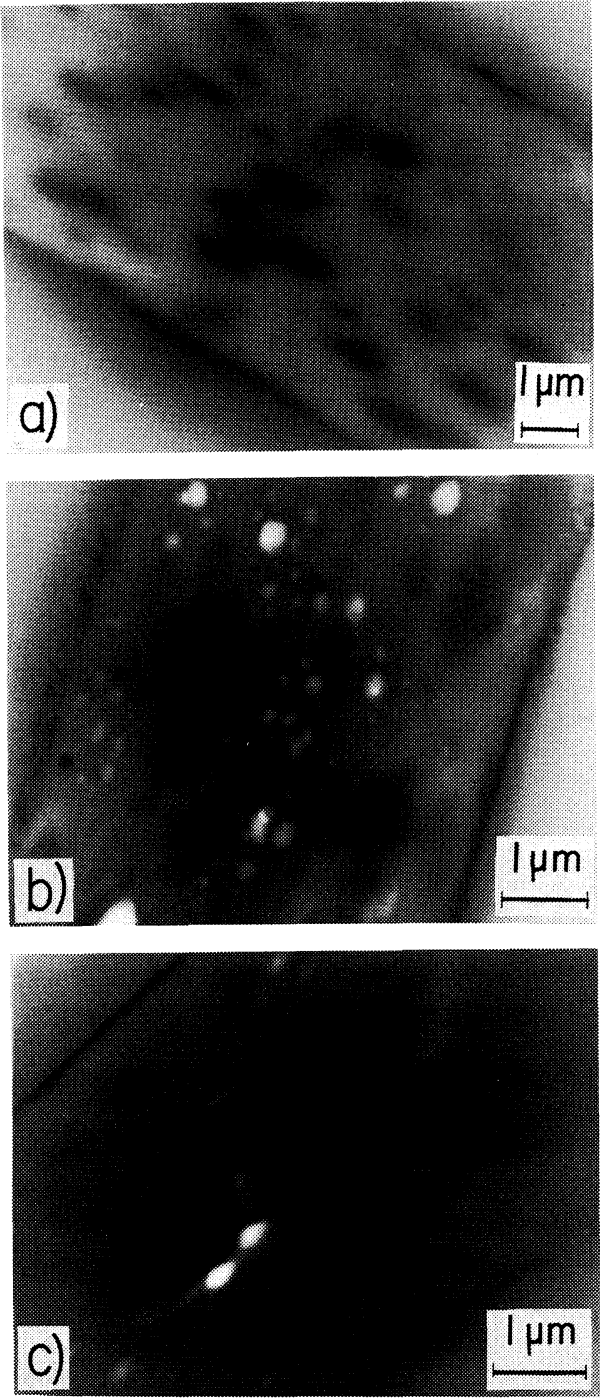

Figure 6. Transmission electron micrographs of the blended membranes: (a) b-PMA 1; (b) b-PMA 2; (c) bPMA 3.

for pure water ${ }^{34}$ indicates that, on both DSC curves, the sharp peaks at higher temperatures can be assigned to free water. The peaks at lower temperatures, thus, can be assigned to water interacting weakly with polymer molecules, i.e., intermediate water. Even in the intermediate water, there exists water differing in the strength of its interaction with polymer molecules, i.e., relatively weakly interac-

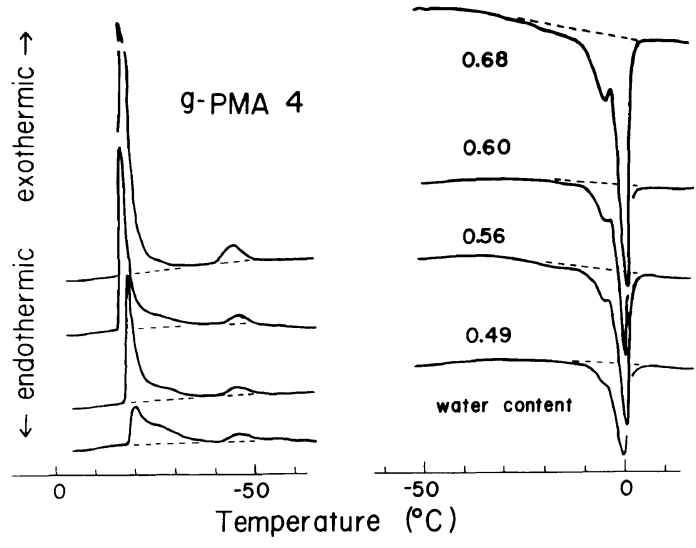

Figure 7. DSC freezing and melting curves for the g-PMA 4 membrane of differing water content.

ting and relatively strongly interacting water. $^{19,22,28}$ The existence of several states of freezing water appeared more remarkably on the melting curves of the Cuprophan membrane. ${ }^{34}$

As reported in the previous paper, ${ }^{34}$ the grafting of hydrophobic AN onto cellulose influenced the states of water in membranes remarkably. In the case of H-GE membranes, the peak for relatively strongly interacting water disappeared and that for relatively weakly interacting water appeared. A comparison of the endothermic curve of the gPMA 4 membrane with that of the cellulose membrane $^{34}$ indicates the decrease in relatively strongly interacting water peak at around $-20^{\circ} \mathrm{C}$ and the appearence of the small peak at around $-10^{\circ} \mathrm{C}$, showing that the influence of the grafting of MA onto cellulose is also recognized.

In Figure 7, the free water peak decreases sharply and shifts toward lower temperatures with decreasing water content but the relatively strongly interacting water peak hardly decreases and shifts very little. The shift of peak temperature is shown more clearly in Figure 8. Each peak temperature shifts toward lower temperatures with decreasing water content and the free water peak on the exothermic curves sharply changes at around 0.7 water 


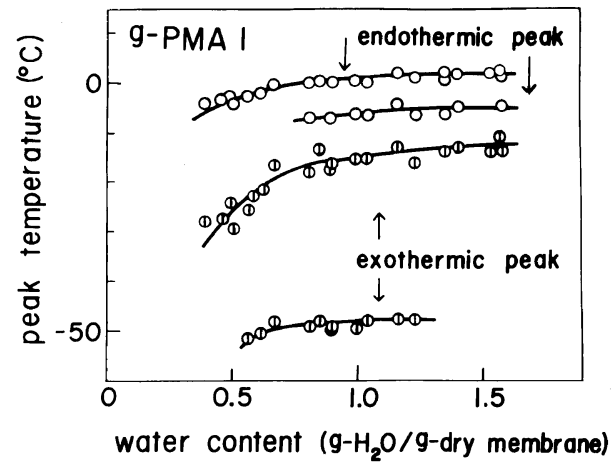

Figure 8. Effects of water content on the endothermic peak $(\bigcirc)$ and exothermic peak temperatures (D).

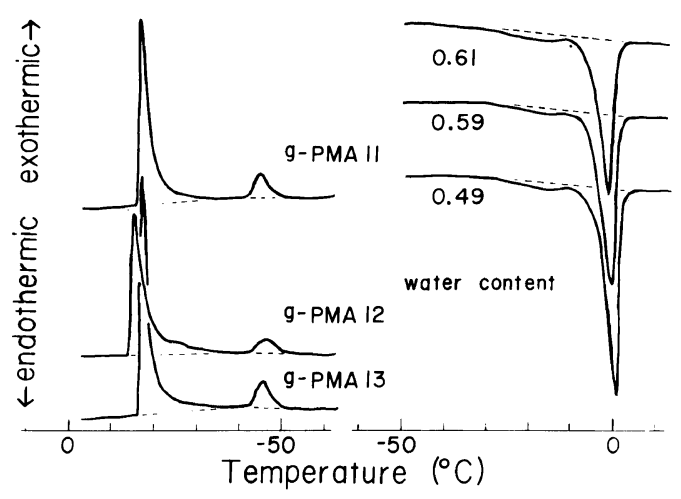

Figure 9. DSC freezing and melting curves for the AIBN membranes.

content. Such a peak temperature shift has been also reported for other polymer membranes, ${ }^{19,20,24,28-30,34}$ indicating that the water molecules interacting more weakly with polymer molecules decrease faster with decreasing total water content than those interacting more strongly.

Figure 9 shows the DSC curves of the AIBN membranes. The features of freezing curves are nearly the same as those of the APS membranes but the endothermic peak at around $-10^{\circ} \mathrm{C}$ has disappeared. Moreover, it should be noted that the melting and freezing curves are similar to those of the cellulose membrane. ${ }^{34}$

Figure 10 shows the DSC curves of the blended membranes. The melting curves of

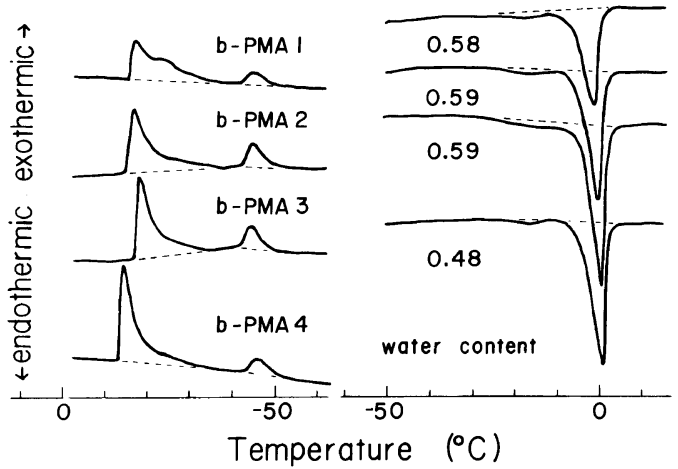

Figure 10. DSC freezing and melting curves for the blended membranes.

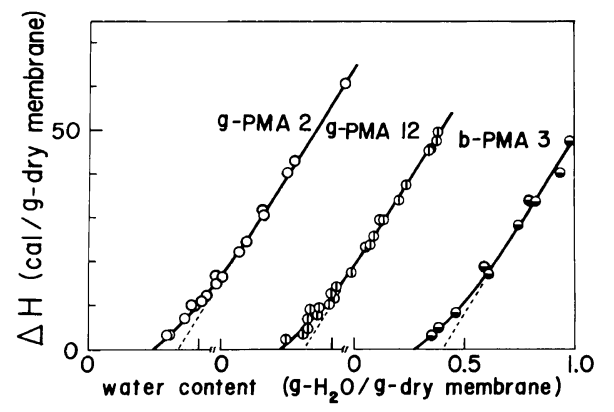

Figure 11. Total water content dependence of the heat of melting of freezing water for various membranes: $(O)$ g-PMA 2; (1) g-PMA 12; (O) b-PMA 3.

the blended membranes are similar to those of the AIBN membranes; no peak for relatively weakly interacting water can be seen. However, the tailing of exothermic free water peaks for the blended membranes appears more pronounced than that for the AIBN membranes. Such tailing has been also recognized for the PAN-cellulose blended membranes.

In Figure 7, there exists two exothermic peaks on the freezing curves but three endothermic peaks on the melting curves. In Figures 9 and 10, both endothermic curves are similar to each other but they are not exothermic curves. Such a difference in both curves was also recognized in the previous paper. ${ }^{34}$ To understand better the states of water in membranes, representation of both curves is desirable..$^{22,29}$ 
Table II. DSC results for cellulosic, grafted, and blended membranes

\begin{tabular}{|c|c|c|c|c|c|c|}
\hline \multirow{4}{*}{ Sample code } & \multirow{3}{*}{$\begin{array}{c}\begin{array}{c}\text { Equilibrium } \\
\text { water content }\end{array} \\
W_{\mathrm{DSC}}\end{array}$} & \multirow{3}{*}{$\begin{array}{c}\begin{array}{c}\text { Equilibrium } \\
\text { nonfreezing } \\
\text { water content }\end{array} \\
W_{\text {non }}\end{array}$} & \multicolumn{4}{|c|}{ Equilibrium freezing water content } \\
\hline & & & \multirow[b]{2}{*}{$W_{\mathrm{DSC}}-W_{\text {non }}$} & \multirow{2}{*}{$\begin{array}{l}\text { Free } \\
\text { water }\end{array}$} & \multicolumn{2}{|c|}{ Intermediate water } \\
\hline & & & & & $\begin{array}{c}\text { Weakly } \\
\text { interacting }\end{array}$ & $\begin{array}{l}\text { Strongly } \\
\text { interacting }\end{array}$ \\
\hline & \multicolumn{6}{|c|}{ g- $\mathrm{H}_{2} \mathrm{O} / \mathrm{g}$-dry membrane } \\
\hline \multicolumn{7}{|l|}{ Cellulosic } \\
\hline Cuprophan & 1.0 & 0.49 & 0.51 & $0.24(47 \%)$ & $0.14(27 \%)$ & $0.13(26 \%)$ \\
\hline Cellulose & 0.70 & 0.45 & 0.25 & $0.22(88 \%)$ & 0 & $0.03(12 \%)$ \\
\hline \multicolumn{7}{|l|}{ APS Membrane } \\
\hline g-PMA 1 & 0.70 & 0.45 & 0.25 & $0.21(87 \%)$ & $0.03(10 \%)$ & $0.01(3 \%)$ \\
\hline g-PMA 2 & 0.66 & 0.41 & 0.25 & $0.20(80 \%)$ & $0.04(16 \%)$ & $0.01(5 \%)$ \\
\hline g-PMA 3 & 0.59 & 0.33 & 0.26 & $0.19(74 \%)$ & $0.06(21 \%)$ & $0.01(5 \%)$ \\
\hline g-PMA 4 & 0.62 & 0.33 & 0.29 & $0.22(74 \%)$ & $0.06(21 \%)$ & $0.01(5 \%)$ \\
\hline AIBN Membrane & & • & & & & \\
\hline g-PMA 11 & 0.63 & 0.40 & 0.23 & $0.20(89 \%)$ & 0 & $0.03(11 \%)$ \\
\hline g-PMA 12 & 0.57 & 0.37 & 0.20 & $0.18(90 \%)$ & 0 & $0.02(10 \%)$ \\
\hline g-PMA 13 & 0.47 & 0.30 & 0.17 & $0.15(90 \%)$ & 0 & $0.02(10 \%)$ \\
\hline \multicolumn{7}{|l|}{ Blended membrane } \\
\hline b-PMA 1 & 0.65 & 0.43 & 0.22 & $0.20(89 \%)$ & 0 & $0.02(11 \%)$ \\
\hline b-PMA 2 & 0.65 & 0.42 & 0.23 & $0.21(91 \%)$ & 0 & $0.02(9 \%)$ \\
\hline b-PMA 3 & 0.60 & 0.40 & 0.20 & $0.18(91 \%)$ & 0 & $0.02(9 \%)$ \\
\hline b-PMA 4 & 0.50 & 0.31 & 0.19 & $0.18(93 \%)$ & 0 & $0.01(7 \%)$ \\
\hline
\end{tabular}

Figure 11 shows the relationship between water content and heat of melting of freezing water, $\Delta H$, determined from the area under the endothermic curve. The data points for each membrane do not follow a straight line but give a curve convexing downward at lower water content. The slope of each straight part of the curve is approximately equal to the specific heat of melting of pure water. This indicates that the amount of nonfreezing water decreases at lower water content under the assumption of equality between the specific heat of melting of freezing water in membranes and that of pure water. The equilibrium nonfreezing water content, $W_{\text {non }}$, was estimated by extrapolation of the straight part to $\Delta H=0$.

As mentioned in our previous paper, ${ }^{34}$ the equilibrium water content determined by blotting water on the membrane surfaces involves considerable experimental error. The equilibrium water content was expressed as the water content where the amount of nonfreezing water becomes constant, i.e., a water content such that the plots of $\Delta H$ against it deviate from the straight line. In Figure 8, the peak temperature has changed sharply at a certain water content. It was found that there exists good correlation between the water content where the curve deviates from a straight line in Figure 11 and that where the curve changes sharply in Figure 8. Thus in this study, their average value was used as the equilibrium water content estimated by the DSC method, $W_{\text {DSC. }}$. The results are listed in Table II. Irrespective of the kind of membrane, the value of $W_{\text {DSC }}$ decreases with increasing PMA content but the superiority of permeability through the APS membranes shown in Fig- 
ures 1-3 still cannot be explained.

Water in membranes includes nonfreezing water thought to be not appreciably related to the permeation of solutes. ${ }^{31,32}$ The water related to the permeation of solutes, should thus be estimated to elucidate the difference in permeability through membranes. The freezing water content was calculated from the difference in the amounts of $W_{\text {DSC }}$ and $W_{\text {non }}$. As can be seen from Table II, the freezing water content of the APS membranes increases slightly with increasing PMA content but those of the AIBN and blended membranes decrease. Furthermore, a comparison of the same PMA content levels indicates that the freezing water content of the blended membranes is a little higher than that of the AIBN membranes. These results explain the PMA content dependence of permeability shown in Figures 2 and 3.

In Figure 1, the permeabilities of all solutes investigated through the g-PMA 4 membrane are not necessarily superior to those through the cellulose membrane. The permeability of raffinose through the g-PMA 4 membrane is superior to that through the Cuprophan membrane but the freezing water content of the former is smaller than that of the latter. In Figures 2 and 3, the dependence of permeability on the PMA content differs with the permeating solute itself. These results imply that the freezing water content is not the only measure of solute diffusive permeability and that the water regions where a solute can permeate differ with the solute. The endothermic curves for various membranes indicated in Figures 7, 9, and 10 can be resolved roughly into each type of water. The results are also listed in Table II. The fraction of strongly interacting water of APS membranes is smaller than those of AIBN, blended, and cellulosic membranes. This is probably because that, in the APS membranes indicating fine microphase separated structures, the hydrophobic polymer chains being present around the hydrophilic cellulose chains effect the states of intermediate water. On the other hand, the fractions of relatively strongly interacting water for cellulose, AIBN, and blended membranes are nearly equal to each other. The superiority of permeability through the APS membranes, thus, is thought to be correlated with the decrease in relatively strongly interacting water. This was also found in our previous study. ${ }^{34}$

The free water content of the g-PMA 4 membrane, however, is a little smaller than that of the Cuprophan membrane. It has been reported $^{23,26,42,43}$ that solutes having water structure breaking hydrophilic groups are closely accessible to polymer chains. Moreover, it has been reported ${ }^{1,2,5}$ that the water content of membranes equilibrated in pure water differs from that equilibrated in solutions and that the partition coefficient of solutes varies with the solute. In order to clarify the relationship between the diffusive permeability of solutes through membranes and the states of water in them, an investigation on the interaction between permeating solutes, membrane substrates, and water in membranes will be conducted.

\section{REFERENCES}

1. H. Yasuda, C. E. Lamaze, and L. D. Ikenberry, Makromol. Chem., 118, 19 (1968).

2. H. Yasuda, L. D. Ikenberry, and C. E. Lamaze, Makromol. Chem., 125, 108 (1969).

3. H. Yasuda, A. Peterlin. C. K. Colton, K. A. Smith, and E. W. Merrill, Makromol. Chem., 126, 177 (1969).

4. J. Komiyama and R. M. Fuoss, Proc. Natl. Acad. Sci., U.S.A., 69, 829 (1972).

5. S. Takigami, Y. Maeda, and Y. Nakamura, J. Appl. Polym. Sci., 24, 1419 (1979).

6. S. Takigami, M. Nakamura, and Y. Nakamura, Polymer, 25, 963 (1984).

7. S. W. Kim, J. R. Cardinal, S. J. Wisniewski, and G. M. Zentner, "Water in Polymers," S. P. Rowland, Ed., American Chemical Society, Washington D. C., 1980, p 347.

8. Y. Kojima, K. Furuhata, and K. Miyasaka, J. Appl. Polym. Sci., 29, 533 (1984).

9. F. C. Magne, H. J. Portas, and H. Wakeham, J. Am. Chem. Soc., 69, 1896 (1968). 
10. A. Odajima, J. Phys. Soc. Jpn., 14, 308 (1959).

11. R. E. Dehl, J. Chem. Phys., 48, 831 (1968).

12. T. A. Jadwin, A. S. Hoffman, and W. R. Vieth, J. Appl. Polym. Sci., 14, 1339 (1970).

13. M. A. Frommer and D. Lancet, J. Appl. Polym. Sci., 16, 1295 (1972).

14. S. Krishnamurthy, D. McIntyre, E. R. Santee, Jr., and C. W. Wilson, III, J. Polym. Sci., 11, 427 (1973).

15. H. G. Burghoff and W. Pusch, J. Appl. Polym. Sci., 23, 473 (1979).

16. M. Aizawa and S. Suzuki, Bull. Chem. Soc. Jpn., 44, 2967 (1971).

17. M. F. Froix and R. Nelson, Macromolecules, 8, 726 (1975).

18. H. B. Lee, M. S. Jhon, J. D. Andrade, J. Colloid Interface Sci., 51, 225 (1975).

19. Y. Taniguchi and S. Horigome, J. Appl. Polym. Sci., 19, 2743 (1975).

20. R. A. Nelson, J. Appl. Polym. Sci., 21, 645 (1977).

21. E. Ahad, J. Appl. Polym. Sci., 22, 1665 (1978).

22. D. G. Pedley and J. B. Tighe, Br. Polym. J., 11, 130 (1979).

23. S. J. Wisniewski and S. W. Kim, J. Membrane Sci., 6, 299 (1980).

24. C. Lemoyne, C. Friedrich, J. L. Halary, C. Noël, and L. Monnerie, J. Appl. Polym. Sci., 25, 1883 (1980).

25. Y. K. Sung, D. E. Gregonis, M. S. Jhon, and J. D. Andrade, J. Appl. Polym. Sci., 26, 3719 (1981).

26. S. C. Yoon and M. S. Jhon, J. Appl. Polym. Sci., 27, 3133 (1982).

27. I. D. Maxwell and R. A. Pethrick, J. Appl. Polym. Sci., 28, 2363 (1983).

28. H. Ohno, M. Shibayama, and E. Tsuchida,
Makromol. Chem., 184, 1017 (1983).

29. K. Nakamura, T. Hatakeyama, and H. Hatakeyama, Polymer, 24, 871 (1983).

30. T. Hatakeyama, A. Yamauchi, and H. Hatakeyama, Eur. Polym. J., 20, 61 (1984).

31. G. N. Ling, "Water Structure at the Water-Polymer Interface," H. H. G. Jellinek, Ed., Plenum, New York, 1972, p 4.

32. T. Matsuura, "Gouseimaku no Kiso," Kitami Shobo, Tokyo, 1981.

33. N. Nishioka, K. Watase, K. Arimura, K. Kosai, and M. Uno, Polym. J., 16, 867 (1984).

34. N. Nishioka, S. Yoshimi, T. Iwaguchi, and K. Kosai, Polym. J., 16, 877 (1984).

35. N. Nishioka and K. Kosai, Polym. J., 13, 1125 (1981).

36. N. Nishioka, K. Minami, and K. Kosai, Polym. J., 15, 591 (1983).

37. G. Jayma and P. Kleppe, Papier, 15, 492 (1961).

38. L. Trossareli and G, Saini, Atti Accad. Sci. Torino, Classe Sci. Fis., Mat. Nat., 90, 431 (1955-56).

39. F. Ide, "Graft Jugo to sono Oyo," Kobunshi Kankokai, Kyoto, 1977.

40. G. Allen, C. Booth, S. J. Hurst, and C. Price, Polymer, 8, 391 (1967).

41. S. Kraus, "Polymer Blends," Vol. 1, D. R. Paul and S. Newman, Ed., Academic Press, New York, 1978, p 15.

42. E. G. Finer, F. Franks, and M. J. Tait, J. Am. Chem. Soc., 94, 4424 (1972).

43. O. D. Bonner, J. M. Badnarek, and R. K. Arisman, J. Am. Chem. Soc., 99, 2898 (1977). 